\title{
Influência do sistema de criação em piso sobre cama e gaiola sobre as características ósseas e a qualidade físico-química e microbiológica de ovos de galinhas
}

[Influence of the floor and cage creation system on the bony characteristics and the physical-chemical and microbiological quality of hen eggs]

\author{
T.L. Reis, J.C.P. Quintero, R.H. Luchese, G.H. Adler, \\ C.V. Freitas Junior, L.G. Silva, L.F.L. Calixto
}

Universidade Federal Rural do Rio de Janeiro - Seropédica, RJ
Túlio Leite Reis https://orcid.org/0000-0003-2141-8740 Juan Carlos Palomino Quintero https://orcid.org/0000-0003-4342-5490 Rosa Luchese https://orcid.org/0000-0002-2059-1368 Germano Adler https://orcid.org/0000-0003-2120-0557 Claudinei Junio (1//) Jid.org/0000-0001-5782-7293 Letycia Gama da Silva https://orcid.org/0000-0003-1954-5484 https://orcid.org/0000-0002-6448-0643

\section{RESUMO}

O experimento foi realizado no setor de avicultura/UFRRJ, utilizando 348 galinhas semipesadas (linhagem Dekalb Brown), com 52 semanas de idade, criadas sob dois sistemas de produção: cage-free e em gaiolas. Os dados obtidos pela análise físico-química e microbiológica dos ovos e a resistência óssea à quebra foram submetidos à análise de variância. No caso de ocorrerem efeitos dos diferentes sistemas de produção, foi aplicado o teste de Tukey a 5\% de probabilidade para comparação das médias. A qualidade físico-química foi igualmente favorecida pelos dois sistemas de produção, indicando que as circunstâncias experimentais propiciaram condições adequadas para a formação de ovos de boa qualidade. O sistema de gaiola não desfavoreceu as características ósseas das galinhas, apontando que, em densidades adequadas, a gaiola pode não exercer um fator prejudicial para a qualidade óssea. O sistema de produção cage-free piorou a contaminação da casca, comprovando que ovos postos em ninhos são mais contaminados em comparação aos produzidos em gaiolas.

Palavras-chave: microbiologia da casca, qualidade dos ovos, resistência óssea

\begin{abstract}
The experiment was carried out in the poultry sector / UFRRJ, using 348 semi-heavy hens (Dekalb Brown line), 52 weeks old, raised under two cage-free production systems and cages. The data obtained by the physical-chemical and microbiological analysis of the eggs and the bone resistance to the break were submitted to analysis of variance, in case of effects of the different production systems, the Tukey's test was applied at 5\% of probability for comparison of the means. The physical-chemical quality was also favored by the two production systems, indicating that the experimental circumstances provided adequate conditions for the formation of good quality eggs. The cage system did not disfavor the bony characteristics of the hens, indicating that at suitable densities, the cage may not exert a detrimental factor to bone quality. The cage-free production system worsened shell contamination by proving that nesting eggs are more contaminated compared to those produced in cages.
\end{abstract}

Keywords: microbiology of shell, egg quality, bone strength

\section{INTRODUÇÃO}

O principal sistema de produção de ovos no Brasil é aquele em que as aves são produzidas em granjas comerciais, de forma intensiva, em baterias de gaiolas convencionais ou automatizadas, em escala industrial (Silva Filho et al., 2015). Esse tipo de produção intensificada foi possível mediante a modernização dos equipamentos convencionais e sua mecanização, o que aprimorou a produtividade por meio da melhor distribuição de ração, de adequado fornecimento de água, da otimização na coleta de ovos e do apropriado manejo dos dejetos, medidas que melhoraram a higiene e, consequentemente, a segurança alimentar na

Recebido em 10 de setembro de 2018

Aceito em 24 de janeiro de 2019

E-mail: tulioreis@hotmail.com 
oferta de ovos. No entanto, as próprias características do sistema de criação em gaiolas convencionais fizeram surgir um crescente senso crítico a respeito dos impactos da produção intensiva sobre os animais, o ambiente e o homem. Essa crítica se refere principalmente ao espaço físico oferecido aos animais, bem como à ausência de elementos de enriquecimento ambiental, que impossibilita ou limita o repertório de atividades consideradas importantes para o animal, como seu "comportamento natural", que constitui uma das liberdades a que os animais têm direito. De acordo com Praes et $a l$. (2012), a objeção quanto à criação em gaiolas convencionais é focada sobretudo na restrição da liberdade das aves. Os autores defendem que as aves devem exercer seus comportamentos naturais, considerados primordiais para garantir a saúde e o conforto, como ciscar, tomar banho de areia, empoleirar e poder colocar seus ovos em ninhos. Além do pequeno espaço, a gaiola convencional gera um grande desconforto para as aves, podendo causar canibalismo, problema nas patas e fragilidade óssea.

Apesar das considerações e argumentações supracitadas, a criação em sistemas de gaiolas para produção de ovos, de acordo com Tauson (2005), é predominante em todo o mundo, com exceção de poucos países onde existe legislação contra seu uso. Paralelamente a essa polêmica, o consumo de ovos in natura vem demonstrando expansão com dinamismo na maior parte dos países emergentes. Nos países mais desenvolvidos e em alguns emergentes que já possuem um elevado consumo per capita, essa expansão tem sido mais lenta; em contrapartida, a preocupação com o bem-estar das aves impulsiona mudanças do formato convencional de produção de ovos tanto por meio de alterações legislativas, como no caso da UE, quanto por exigências de empresas e consumidores (Amaral et al., 2015). Nesse contexto, nos países desenvolvidos, a predominância de sistemas de produção em gaiolas convencionais vem perdendo espaço para sistemas de produção alternativos, como aqueles de gaiolas enriquecidas, aqueles em que as aves são criadas em piso com cama de maravalha (cage-free) e aqueles que permitem acesso a áreas de pasto (free-range). No entanto, no Brasil, esse é ainda um mercado incipiente, que vem enfrentando dificuldades em se estabelecer, principalmente pelos altos preços do produto final provindo desses sistemas alternativos, além da falta de informação tanto de alguns produtores como da maioria dos consumidores, que não sabem quais são as diferenças de cada produto e desconhecem a razão pela qual os preços variam tanto de um para outro (Pasian e Gameiro, 2007).

No que se refere à qualidade físico-química de ovos produzidos em diferentes sistemas de produção, a literatura tem registrado problemas de deficiência de minerais, tanto interna quanto externamente, tais como menor concentração em ovos produzidos por aves criadas em sistemas livres de gaiolas, resultantes de uma maior dificuldade da ave em garantir uma adequada ingestão de nutrientes, por ser criada solta e sem um rigoroso arraçoamento (Fraser e Brain, 1994). Esse problema pode afetar também a qualidade óssea, especialmente em poedeiras, cuja exigência de cálcio é extremamente elevada, particularmente durante o período ativo de formação da casca (Almeida Paz et al., 2009), portanto a ingestão de uma ração desbalanceada provocaria uma baixa concentração de cálcio no sangue, que poderia resultar em maior fragilidade óssea. Outra preocupação quanto a essa nova modalidade de sistema de produção refere-se à área da segurança alimentar, especificamente pela questão da contaminação via cama de ninho, que constitui uma das formas prevalentes de entrada de contaminantes nos ovos. As excretas são as principais fontes de contaminação da casca, durante a oviposição, sobretudo quando a casca fica exposta ao ninho que já está contaminado pelas excretas das galinhas. Por esse motivo, de acordo com Galvão (2013), a segurança microbiológica de ovos produzidos em sistemas convencionais de gaiolas é maior do que a de ovos produzidos por galinhas criadas em sistemas ao ar livre, que exigem que a postura seja realizada nos ninhos.

Em razão do discutido, idealizou-se esta pesquisa, a fim de se avaliar a qualidade físicoquímica e microbiológica de ovos, além das características ósseas de galinhas produzidas em sistema convencional de gaiolas e no sistema alternativo (cage-free).

\section{MATERIAL E MÉTODOS} Esta pesquisa foi autorizada pelo
Ceua/UFRRJ/IZ, 23083.010963/2017-09. O experimento foi 
realizado no galpão experimental do Setor de Avicultura da Universidade Federal Rural do Rio de Janeiro (UFRRJ). Foram alojadas 348 galinhas semipesadas (linhagem Dekalb Brown), com 52 semanas de idade, distribuídas em dois tratamentos caracterizados pelos sistemas de produção (cage-free e gaiola). Um total de 144 aves foram alojadas no sistema gaiola tipo piramidal, com densidade de $750 \mathrm{~cm}^{2} /$ ave, com bebedouro tipo nipple e comedouro linear, e as 204 aves restantes foram alojadas no sistema cage-free, com cama de maravalha e densidade de 10 aves $/ \mathrm{m}^{2}$, com comedouros tubulares, bebedouro pendular e ninhos para postura dos ovos. As aves foram alimentadas com rações isoproteicas e isoenergéticas, formuladas à base de milho e farelo de soja, atendendo os níveis estabelecidos por Rostagno (2011). Após um período de 14 dias de adaptação das aves ao sistema de produção, iniciou-se o período experimental, que compreendeu sete ciclos de 28 dias cada.

Para avaliação da qualidade físico-química, a cada ciclo de 28 dias foi coletada, ao acaso, uma amostra de 30 ovos de cada tratamento nos dois últimos dias de cada ciclo, totalizando 60 ovos/tratamento/ciclo. Esses ovos foram conduzidos ao Laboratório de Análise de Produtos de Origem Animal (Lapoa) do Instituto de Zootecnia da UFRRJ, onde foram analisados, totalizando, ao final do período experimental, 420 ovos. As metodologias utilizadas para avaliação da qualidade físico-química dos ovos foram as seguintes: unidade Haugh (Haugh, 1937), índice de gema, porcentagens dos componentes do ovo, pigmentação da gema, $\mathrm{pH}$ da gema e do albúmen e espessura da casca. Para avaliação da qualidade óssea, foram utilizadas as técnicas de resistência óssea à quebra, índice de Seedor e quantidade de material mineral dos ossos.

A unidade Haugh foi determinada pela equação: $\mathrm{UH}=100 \log \left(\mathrm{H}+7,57-1,7 \mathrm{~W}^{0,37}\right)$ (Eisen et al., 1962), em que: $\mathrm{H}=$ altura do albúmen denso, medida com o auxílio de um micrômetro tripé $(\mathrm{mm})$; e $\mathrm{W}=$ peso do ovo $(\mathrm{g})$. O índice da gema foi calculado pela razão entre a altura e o diâmetro da gema, de forma que a gema e o albúmen foram separados, para ser medida a altura da gema com o auxílio de um micrômetro tripé, e o diâmetro com um paquímetro manual. Para o cálculo das porcentagens dos componentes do ovo (albúmen, gema e casca), as gemas foram separadas e pesadas em balança digital com precisão de $0,01 \mathrm{~g}$. Posteriormente, as cascas foram lavadas para retirada total do albúmen e secas em estufa a $105^{\circ} \mathrm{C}$, por duas horas, para posterior pesagem. $\mathrm{O}$ peso do albúmen foi calculado pela diferença entre o peso total do ovo e o peso da gema mais a casca. A pigmentação da gema foi avaliada utilizandose o leque colorimétrico da Roche, cuja intensidade de pigmentação varia do amareloclaro ao laranja, em uma escala de 1 a 15, sendo 1 referente ao amarelo mais claro e 15 ao laranja mais intenso. As variáveis de qualidade de casca foram avaliadas pela espessura da casca, por meio de um micrômetro. Os valores de espessura foram obtidos pela realização de leituras em dois fragmentos da zona equatorial da casca, e calculou-se a espessura da casca pela média desses dois pontos.

Para avaliação das características ósseas ao final do experimento, com 77 semanas de idade, 20 galinhas (10 aves por tratamento) foram eutanasiadas por deslocamento cervical (Brasil, 2013). As tíbias foram identificadas e congeladas com os tecidos de cobertura (músculo e cartilagem), em freezer, a $-25^{\circ} \mathrm{C}$, até a preparação dos ossos para as análises. Para a realização da desossa, essas foram devidamente identificadas e mergulhadas em água fervente por 10 minutos; posteriormente foram desossadas com o auxílio de bisturi e tesouras, de modo a se retirar todo o material aderido ao osso (Bruno, 2002).

As avaliações de resistência óssea foram realizadas utilizando-se o aparelho de teste de ensaio Stable Micro Systems Texture Analysers, modelo TA.XT plus, ajustado para permitir vão livre da diáfise da tíbia igual a $6,0 \mathrm{~cm}$, sendo o equipamento calibrado com velocidade pré-teste: $2,0 \mathrm{~mm} / \mathrm{s}$; velocidade do teste: $1,0 \mathrm{~mm} / \mathrm{s}$; velocidade pós-teste: $4,0 \mathrm{~mm} / \mathrm{s}$. Um software específico foi utilizado para registrar a força necessária empregada para o rompimento total dos ossos em quilograma-força (kgf) (Faitarone et al., 2012). O índice de Seedor foi obtido da divisão do peso do osso pelo seu comprimento, conforme proposto por Seedor et al. (1991). As tíbias foram medidas em seu maior comprimento das epífises, com o auxílio de um paquímetro, e tiveram seu peso obtido por meio de uma balança semianalítica digital. O percentual de matéria mineral $(\mathrm{MM})$ na matéria natural $(\mathrm{MN})$ e na 
matéria seca (MS) foi realizado no Laboratório de Bromatologia do Departamento de Nutrição Animal e Pastagens do Instituto de Zootecnia da UFRRJ, onde foram pesados os ossos em balança analítica digital, e estes foram secos por 24 horas, em estufa de ventilação forçada a $105^{\circ} \mathrm{C}$; após esfriarem, foram pesados novamente, e a diferença entre esses valores de peso correspondeu ao teor de matéria seca desengordurada, expresso em porcentagem, conforme metodologia descrita por Kim et al. (2004). Posteriormente, essas amostras foram pesadas novamente e levadas à mufla, onde foram submetidas à temperatura de $580^{\circ} \mathrm{C}$, por quatro horas, para obtenção do teor de minerais totais.

A avaliação da qualidade microbiológica da casca foi realizada mediante duas repetições de análises de ovos no Laboratório de Microbiologia do Instituto de Tecnologia da UFRRJ; para cada análise, utilizaram-se 30 ovos frescos provenientes de cada sistema de produção (gaiola e cage-free ), totalizando 120 ovos analisados no total. Foi obtido um pool de swabs com três ovos, perfazendo 10 amostras de cada tratamento, de forma que cada ovo foi submetido a um esfregaço por toda a superfície da casca, com swab estéril umedecido em solução salina peptonada. Os três swabs foram colocados juntos em um tubo contendo $10 \mathrm{~mL}$ de solução salina peptonada e agitados em vórtex. Realizaram-se diluições decimais subsequentes, que foram semeadas em profundidade em placas de ágar para contagem de mesófilos aeróbios. As placas foram incubadas a $35^{\circ} \mathrm{C}$, por 48 horas. $\mathrm{O}$ resultado foi expresso como unidade formadora de colônia/casca de ovo.

Os dados obtidos para análises de qualidade físico-química dos ovos e de resistência óssea foram submetidos à análise de variância utilizando-se o programa BioEstat ${ }^{\circledR}$. Os dados obtidos das contagens de mesófilos aeróbios positivos foram expressos em log unidade formadora de colônia/casca de ovo previamente e, depois, submetidos à mesma análise. Posteriormente, no caso de ocorrerem efeitos dos diferentes sistemas de produção, foi aplicado o teste de Tukey a 5\% de probabilidade, para comparação das médias em todas as variáveis.

\section{RESULTADOS E DISCUSSÃO}

Os sistemas de produção somente influenciaram a porcentagem do albúmen, de modo que as galinhas criadas no sistema cage-free produziram ovos com maior $(\mathrm{P}<0,05)$ porcentagem do albúmen em comparação àquelas que foram criadas no sistema de gaiolas, conforme se observa na Tab. 1. Barbosa Filho et al. (2006) citaram que, em situações de estresse, o sistema de gaiola pode comprometer a incorporação de proteínas durante o processo de formação desse componente dos ovos no oviduto. Esses autores observaram redução do percentual do albúmen em ovos produzidos por poedeiras desafiadas por altas temperaturas. No presente estudo, as aves não foram submetidas a nenhum tratamento de desafio de estresse, no entanto a própria gaiola pode constituir um estresse para a ave em situações como sustos e ruídos, em que pode ocorrer aglomeração de uma ave sobre a outra, na tentativa de fuga, ou mesmo dificuldade de perder calor por condução, etc.

Küçükyılmaz et al. (2012) descrevem várias situações em que houve influência do sistema de produção sobre a qualidade dos ovos, como: maior peso dos ovos produzidos por aves alojadas em gaiolas em virtude de um menor requerimento de energia e nutrientes para mantença em relação ao sistema piso, sendo, assim, direcionados para a produção e a qualidade de ovos. O mesmo fato ocorre com a qualidade de casca, que tem sido descrita como melhor em ovos produzidos por aves criadas no sistema cage-free, pois as galinhas, nesse sistema, podem se deslocar pelos piquetes, o que as fará exercitar o corpo e estimulará a mobilização de nutrientes e energia para o desenvolvimento dos tecidos musculares $\mathrm{e}$ ósseos e, dessa forma, irá requisitar menor mobilização mineral para a produção de tecido ósseo, favorecendo, assim, maior disponibilidade para a produção da casca, além de maior mobilização mineral proveniente do solo. No presente estudo, a espessura da casca se manteve igual nos dois sistemas e, como o consumo de ração não foi mensurado, presumiu-se que as aves criadas no piso possam ter consumido mais ração na tentativa de suprir sua maior exigência nutricional e seus gastos energéticos, conforme observado por Castellini et al. (2004), que, quando criaram galinhas poedeiras em sistemas orgânicos, verificaram maior consumo de ração 
por essas aves em comparação a galinhas criadas em gaiolas, que produziram ovos com iguais valores de peso e espessura das cascas. Outro fato a se ponderar é o de que a densidade de criação adotada especialmente na gaiola $\left(750 \mathrm{~cm}^{2} /\right.$ ave) é considerada como baixa e pode ter contribuído para que as aves produzissem ovos com ótima qualidade, comprovada pelos altos índices (AA, ou seja, acima de 72) obtidos no parâmetro de UH nos ovos provenientes de ambos os sistemas (Egg..., 2000).

Maiores intensidades de pigmentação da gema também foram registradas na literatura (Lewko e Gornowicz, 2011) em ovos produzidos fora das gaiolas e com acesso a piquetes ricos em várias fontes pigmentantes, o que não ocorreu no presente estudo, em que as aves de ambos os sistemas receberam o mesmo tipo de ração, mas aquelas que foram criadas no sistema cage-free não tiveram acesso a piquetes, fatores que justificam a baixa intensidade de pigmentação da gema, a qual, entretanto, ainda atende a preferência do consumidor na maioria das regiões do país, para quem uma boa coloração de gema varia entre 7 e 8 pontos na escala Roche (Lesson e Summers, 2009).

$\mathrm{O}$ mesmo fato ocorreu com a concentração de $\mathrm{pH}$ do albúmen e da gema dos ovos que não apresentaram diferença significativa $(\mathrm{P}>0,05)$ entre os sistemas de produção. Minelli et al. (2007) relataram alteração no pH do albúmen de ovos produzidos em sistema de gaiolas, devido à maior concentração de amônia proveniente do esterco sob a gaiola dessas aves. No presente estudo, o esterco das aves se depositava sobre uma cama de maravalha que era trocada a cada 15 dias, visando à redução do acúmulo de amônia, não sendo observado tal efeito.

Tabela 1. Peso do ovo, índice da gema (IG), cor da gema, porcentagem da gema (\% gema), porcentagem do albúmen (\% albúmen), porcentagem da casca (\% casca), espessura da casca (Esp. casca), unidade Haugh (UH), pH albúmen e pH da gema dos ovos de galinhas criadas em dois sistemas de produção

\begin{tabular}{lllllllllll}
\hline & $\begin{array}{l}\text { Peso } \\
\text { ovo }\end{array}$ & IG & $\begin{array}{l}\text { Cor } \\
\text { gema }\end{array}$ & $\begin{array}{l}\% \\
\text { gema }\end{array}$ & $\begin{array}{l}\% \\
\text { albúmen }\end{array}$ & $\begin{array}{l}\% \\
\text { casca }\end{array}$ & $\begin{array}{l}\text { Esp. } \\
\text { casca }\end{array}$ & UH & $\begin{array}{l}\text { pH } \\
\text { albúme } \\
\text { n }\end{array}$ & $\begin{array}{l}\text { pH } \\
\text { gema }\end{array}$ \\
\hline $\begin{array}{l}\text { Cage- } \\
\text { free }\end{array}$ & 61,08 & 0,43 & 7,52 & 26,55 & 63,83 a & 9,66 & 0,39 & 100,02 & 8,03 & 6,00 \\
$\begin{array}{l}\text { Gaiola } \\
\text { p-valor }\end{array}$ & 62,00 & 0,43 & 7,46 & 26,55 & $62,52 b$ & 9,74 & 0,39 & 99,89 & 8,26 & 6,05 \\
CV & NS & NS & NS & $<0,0001$ & NS & NS & NS & NS & NS \\
$(\%)$ & 3,98 & 2,99 & 7,37 & 0,94 & 3,33 & 1,73 & 3,15 & 1,82 & 10,32 & 1,63 \\
\hline
\end{tabular}

Médias seguidas por letras diferentes minúsculas na coluna diferem a 5\% pelo teste de Tukey. NS = não significativo. $\mathrm{CV}=$ coeficiente de variação.

A Tab. 2 apresenta os parâmetros de qualidade óssea das aves. As características ósseas foram influenciadas pelos sistemas de criação, de forma que a resistência à quebra e a concentração de matéria mineral na matéria natural e na matéria seca foram maiores $(\mathrm{P}<0,05)$ nos ossos das aves criadas em sistema de produção de gaiolas. $\mathrm{O}$ índice de Seedor não apresentou diferenças significativas entre os dois sistemas de produção (P>0,05). Gregory et al. (1990) descreveram situações de maior fragilidade óssea em galinhas produzidas em sistemas alternativos de criação (free-range) em comparação a aves produzidas em gaiolas, justificando que aves criadas no piso podem sofrer falhas durante o voo, podem cair ou serem empurradas para fora dos poleiros, provocando maior debilidade óssea e incidência de lesões crônicas. Também foram descritas situações opostas, tais como as relatadas por Deaton et al. (1985), que, ao avaliarem a estrutura esquelética de aves, observaram que tíbias de frangas criadas no piso possuíam estrutura óssea mais forte e com maior porcentagem de cinzas ósseas do que as tíbias das frangas criadas em gaiolas. 
Tabela 2. Índice de Seedor, resistência à quebra $(\mathrm{kgF})$, porcentagem de matéria mineral na matéria natural (\% MM na $\mathrm{MN}$ ) e porcentagem de matéria mineral na matéria seca (\%MM na MS) de ossos de galinhas semipesadas criadas em dois sistemas de produção

\begin{tabular}{lllll} 
& Índice de Seedor & Resistência à quebra $(\mathrm{kgF})$ & $\% \mathrm{MM}$ na $\mathrm{MN}$ & $\% \mathrm{MM}$ na MS \\
\hline Cage-free & 93,43 & $12,14 \mathrm{~b}$ & $37,57 \mathrm{~b}$ & $48,62 \mathrm{~b}$ \\
Gaiola & 97,47 & $17,35 \mathrm{a}$ & $42,85 \mathrm{a}$ & $53,15 \mathrm{a}$ \\
p-valor & $\mathrm{NS}$ & 0,0001 & 0,004 & 0,02 \\
CV $(\%)$ & 7,19 & 22,57 & 10,69 & 9,01 \\
\hline
\end{tabular}

Médias seguidas por letras diferentes minúsculas na coluna diferem a 5\% pelo teste de Tukey. NS = não significativo. $\mathrm{CV}=$ coeficiente de variação.

Fato é que os sistemas de criação no piso permitem que as aves possam tanto se deslocar buscando luz solar, favorecendo, portanto, o aporte de vitamina $\mathrm{D}$, quanto se abrigar melhor do sol, além de elas poderem desenvolver maior nível de atividade e capacidade de movimentação, bem como utilizar a própria cama como fonte de fibras e minerais, melhorando o metabolismo mineral (Rizzi et al., 2006). No presente estudo, a densidade baixa $\left(750 \mathrm{~cm}^{2} / \mathrm{ave}\right)$ das aves criadas no sistema gaiola possibilitou a elas uma certa mobilidade e atividade, o que pode ter prevenido maior fragilidade óssea e susceptibilidade a fraturas. Segundo Lay et al. (2011), o tipo de criação da ave influencia diretamente a qualidade óssea dela, no entanto o fator mais importante é a quantidade de atividade física realizada pela poedeira; então, aves criadas com maior espaço nas gaiolas podem apresentar boas características ósseas.

A Tab. 3 apresenta os resultados referentes à qualidade microbiológica dos ovos, a qual foi influenciada pelos sistemas produtivos, de forma que ovos produzidos por galinhas criadas em cage-free apresentaram maiores $(\mathrm{P}<0,05)$ taxas de contaminação de mesófilos aeróbios em comparação àquelas que foram criadas no sistema de gaiolas. Ovos colocados em ninhos são comumente mais sujos com as excretas das galinhas e possivelmente podem possuir mais agentes patogênicos que ovos produzidos em sistemas de gaiolas (Galvão, 2013). Em sistemas alternativos, a ave coloca seus ovos em ninhos cobertos com cama (geralmente de maravalha), a qual geralmente está contaminada com as excretas das aves, contaminando seus ovos. Quando as aves são criadas em gaiolas, os ovos postos no fundo delas conseguem rolar até o prolongamento da gaiola, escapando do contato com as excretas da ave e mantendo suas cascas com menores níveis de contaminação. Esses resultados corroboram os achados de De Reu et al. (2006), que encontraram, em média, uma maior contaminação da casca, medida pela contagem total de bactérias aeróbicas, em ovos provenientes de sistemas em que a ave foi criada em sistema cage-free, em comparação aos sistemas de gaiola (respectivamente 5,46 contra $5,08 \log$ UFC/casca de ovo).

Tabela 3. Contagem de mesófilos aeróbios positivos (expressos em log UFC/casca) de ovos de galinhas semipesadas criadas em dois sistemas de produção

Contagem de mesófilos aeróbios positivos (log UFC/casca)

\begin{tabular}{ll}
\hline Cage-free & 5.3709 a \\
Gaiola & $4.2346 \mathrm{~b}$ \\
p-valor & 0,0015 \\
CV $(\%)$ & 24,27 \\
\hline
\end{tabular}

Médias seguidas por letras diferentes minúsculas na coluna diferem a 5\% pelo teste de Tukey. $\mathrm{CV}=$ coeficiente de variação.

\section{CONCLUSÃO}

A qualidade físico-química dos ovos se manteve igualmente favorecida pelos dois sistemas de produção, havendo somente diferença na porcentagem do albúmen, que ocorreu em maior concentração em ovos produzidos em sistema cage-free. A criação de galinhas em gaiolas permitiu melhor qualidade óssea na densidade de 
alojamento estudada e propiciou melhor qualidade microbiológica dos ovos produzidos.

\section{REFERÊNCIAS}

ALMEIDA PAZ, I.C.L.; MENDES, A.A.; BALOD, A. et al. Efeito do cálcio na qualidade óssea e de ovos de poedeiras. Arch. Zootec., v.58, p.173-183, 2009.

AMARAL, G.; GUIMARAES, D.; NASCIMENTO, J.C. et al. Avicultura de postura: estrutura da cadeia produtiva, panorama do setor no Brasil e no mundo e o apoio do BNDES. BNDES Setorial, n.43, p.167-207, 2015. (Agronegócio).

BARBOSA FILHO, J.A.D.; SILVA, M.A.N.; SILVA, I.J.O.; COELHO, A.A.D. Egg quality in layers housed in different production systems and submitted to two environmental conditions. Rev. Bras. Cienc. Avic., v.8, p.23-28, 2006.

BRUNO, L.G.D. Desenvolvimento ósseo em frangos de corte: influência da restrição alimentar e da temperatura ambiente. 2002. $72 \mathrm{f}$. Tese (Doutorado em Zootecnia) - Faculdade de Ciências Agrárias e Veterinárias, Universidade Estadual de Paulista, Jaboticabal, SP.

BRASIL. Ministério da Ciência Tecnologia e Inovação. Conselho Nacional de Controle de Experimentação Animal. Diretrizes da Prática de Eutanásia do Concea. Brasília, 2013. 54p.

CASTELlinI, C.; MUGNAI, C.; DAL BOSCO, A. et al . Aspetti comportamentali, prestazioni produttive e qualità dell'uovo in galline allevate con il metodo biologico. Riv. Avicolt., v.3, p.4144, 2004.

DE REU, K.; GRIJSPEERDT, K.; HEYNDRICKX, M. et al. Bacterial shell ontamination in the egg collection chains of different housing systems for laying hens. $\mathrm{Br}$. Poult. Sci., v.47, p.163-172, 2006.

DEATON, J.W.; BRANTON, S.L.; LOTT, B.D.; BRAKE, J.D. Noted difference in the digestive system in cage and floor-reared commercial eggtype pullets. Poult. Sci., v.64, p.1035-1037, 1985.

EGG-grading manual. Washington: USDA / Departament of Agriculture, 2000. 56p. (Agricultural Markenting Service, 75).
EISEN, E.J.; BOHREN, B.B.; MCKEAN, H.E. The unit as a measure of egg albumen quality. Poult. Sci., v.41, p.1461-1468, 1962.

FAITARONE, A.B.G.; GARCIA, E.A.; ARTONI, S.M.B. et al. Qualidade óssea de poedeiras comerciais leves alimentadas com rações suplementadas com diferentes óleos vegetais. Vet. Zootec., p.356-365, 2012.

FRASER, A.C.; BRAIN, M.M. A comparison of eggshell structure from birds housed in conventional battery cages and in a modified free range system. In: EUROPEAN POULTRY CONFERENCE, 3., 1994, Glasgow. Proceedings... Glasgow, U.K, [s.n.], 1994. v.1, p.151-152.

GALVÃO, J.A. Ovos produzidos em diferentes sistemas de alojamento: qualidade e segurança microbiológica, parâmetros físicos, validação $e$ utilização de método multiresíduo para detecção de antimicrobianos e pesticidas. 2013. 106f. Tese (Doutorado em Inspeção de Produtos de Origem Animal) - Faculdade de Medicina Veterinária e Zootecnia, Universidade Estadual Paulista, Botucatu, SP.

GREGORY, N.G.; WILKINS, L.J.; ELEPERUMA, S.D. et al. Broken bones in domestic fowls: effect of husbandry system and stunning method in end-oflay hens. Br. Poult. Sci., v.31, p.59-69, 1990.

HAUGH, R.R. The Haugh unit for measuring egg quality. U.S. Egg Poult. Mag., v.43, p.552$555,1937$.

KIM, W.K.; DONALSON, L.M.; HERRERA, P. et al. Effects of different bone preparation methods (fresh, dry, and fat-free dry) on bone parameters and the correlation between bone breaking strength and the other bone parameter. Poult. Sci., v.83, p.1663-1666, 2004.

KÜÇÜKYILMAZ， K.; BOZKURT， M.; HERKEN, E.N. et al. Effects of rearing systems on performance, egg characteristics and immune response in two layer hen genotype. AsianAustralas. J. Anim. Sci., v.25, p.559, 2012.

LAY, D.C.; FULTON, R.M.; HESTER, P.Y. et $a l$. Hen welfare in different housing systems. Poult. Sci., v.90, p.278-294, 2011.

LEESON, S.; SUMMERS, J.D. Commercial poultry nutrition. 3.ed. Nottingham: University Press, 2009. 296p. 
LEWKO, L.; GORNOWICZ, E. Effect of housing system on egg quality in laying hens. Ann. Anim. Sci., v.11, p.607-611, 2011.

MINELLI, G.; SIRRI, F.; FOLEGATTI, E. et al. Egg quality traits of laying hens reared in organic and conventional systems. Ital. J. Anim. Sci., v.6, p.728-730, 2007.

PASIAN, I.M.; GAMEIRO, A.M. Mercado para a criação de poedeiras em sistemas do tipo orgânico, caipira e convencional, In: CONGRESSO DA SOBER: CONHECIMENTOS PARA AGRICULTURA DO FUTURO, 45., 2007, Londrina. Anais... Londrina: Universidade Estadual de Londrina, 2007.

PRAES, M.F.F.M.; JUNQUEIRA, O.M.; PEREIRA, A.A. Prós e contras da proibição da criação de poedeiras em gaiolas. Rev. AviSite, 2012. Disponível em: <http://www.avisite.com.br/cet/trabalhos.php?co digo=144>. Acessado em: 10 abr. 2017.

RIZZI, L.; SIMIOLI, G.; MARTELLI, G.; PAGANELLI R.; SARDI, L. Effects of organic farming on egg quality and welfare of laying hens. In: EURO POULTRY CONFERENCE, 12., 2006, Verona. Proceedings... Verona, [s.n.], 2006. p.10-14.
ROSTAGNO, H.S. Tabelas brasileiras para aves e suínos: composição dos alimentos e exigências nutricionais. 3.ed. Viçosa, Universidade Federal de Viçosa, 2011, p.252.

SEEDOR, J.G.; QUARTUCCIO, H.A.; THOMPSON, D.D. The bisphosphonate alendronate (MK-217) inhibits bone loss due to ovariectomy in rats. J. Bone Miner. Res., v.6, 1991.

SILVA FILHO, C.A.; CALIXTO, L.F.L.; LEMOS, M.J. et al. Qualidade de ovos convencionais e alternativos comercializados na região de Seropédica (RJ). Rev. Academ. Cienc. Anim., v.13, p.177-184, 2015.

TAUSON, R. Management and housing systems for layers-efectson welfare and production. Worlds Poult. Sci. J., v.61, p.477-490, 2005. 